\title{
Evidence for a "Founder Effect" among HIV- infected injection drug users (IDUs) in Pakistan
}

\author{
Mohammad A Rai ${ }^{1}$, Vivek R Nerurkar², Suhail Khoja', Saeed Khan', Richard Yanagihara ${ }^{2,3}$, Arish Rehman', \\ Shahana U Kazmi ${ }^{4}$, Syed $\mathrm{H} \mathrm{Ali}^{1 *}$
}

\begin{abstract}
Background: We have previously reported a HIV-1 subtype A infection in a community of injection drug users (IDUs) in Karachi, Pakistan. We now show that this infection among the IDUs may have originated from a single source.

Methods: Phylogenetic analysis was performed of partial gag sequences, generated using PCR, from 26 HIVpositive IDU samples.

Results: Our results showed formation of a tight monophyletic group with an intra-sequence identity of < $98 \%$ indicating a "founder effect". Our data indicate that the HIV-1 epidemic in this community of IDUs may have been transmitted by an HIV positive overseas contract worker who admitted to having contact with commercial sex workers during stay abroad.
\end{abstract}

Conclusion: Specific measures need to implemented to control transmission of HIV infection in Pakistan through infected migrant workers.

\section{Background}

The first evidence of Human immunodeficiency virus (HIV) infection in Pakistan was reported in 1987 among patients receiving tainted blood or blood products [1]. Having been relatively safe from any indigenous HIV cases for around two decades, this conservative Southeast Asian nation is finally registering isolated HIV outbreaks all over the country.

In 2004, in the remote desert town of Larkana, Pakistan experienced its first HIV outbreak [2]. The implicated populace was a community of Injection Drug Users (IDU), who documented an HIV prevalence approaching an outstanding 27\%. Earlier, HIV prevalence in IDUs was reported by the National AIDS Control Program as bordering around $0.4 \%$ in December, 2003. After the Larkana episode, outbreaks were also recorded in other major cities of Pakistan [3]. The changing trend denotes that the country is transitioning from a low prevalence to a concentrated epidemic stage.

\footnotetext{
* Correspondence: syed.ali@aku.edu
'Department of Biological and Biomedical Sciences, Aga Khan University,

* Correspondence: syed.ali@aku.edu
'Department of Biological and Biomedical Sciences, Aga Khan University, Karachi, Pakistan
}

(C) 2010 Rai et al; licensee BioMed Central Ltd. This is an Open Access article distributed under the terms of the Creative Commons

Apart from IDUs, other high-risk populations including truck drivers [4], commercial sex workers, including Hijras [5] have also been identified in the Pakistani context. Even though very little serological data are available, various knowledge, attitude and practice studies [3,6-9] have demonstrated an increasingly vulnerable position for a devastatingly spread of HIV in these highrisk groups.

Earlier, we have reported an HIV subtype A concentrated epidemic in a community of IDUs in Karachi, Pakistan's largest city [10]. The study presented here is an extension of that previous study on the same community of IDUs. In the previous study we showed that HIV-1 subtype A was the only subtype of HIV prevalent among this community. From the data we gathered, there were indications that this community of IDUs was infected by HIV positive overseas commercial workers (OCW) deported to Pakistan during early nineties [11]. We now present evidence that the subtype A infection in question was a single-source infection, most likely brought into the IDU community by an OCW. 


\section{Methods}

Ethical approval for this study was obtained from the Ethical Review Committee, Aga Khan University, Karachi, Pakistan. HIV-1 positive patients were selected from a community of IDUs in Karachi, the Southern Port City of Pakistan. After obtaining informed consent, 3 $\mathrm{mL}$ of blood was collected from 26 men (mean age, 24 years) previously diagnosed positive for HIV based on sero-testing.

DNA was extracted from the blood samples using methods previously described [10]. PCR amplification was carried out for HIV gag gene using two sets of primers in a nested strategy. The primers used in nested PCR were GOPF (5' CTCTCGACGCAGGACTCG GCTTGC-3', nt 683-706, HXB2) and GOPR (5'CCAATTCCCCCTATCATTTTTGG-3', nt 2382-2404) for the first round of amplification and primers GIPF (5'-GAGGCTAGAAGGAGAGAGATGGG-3', nt 772794) and GIPR (5'-TTATTGTGACGAGGGGTCGT TGCC-3', nt 2269-2292) for the second round of PCR.

The reaction mixture of $25 \mu \mathrm{l}$ for both first and second round PCR contained $1 \times$ PCR buffer $\left(5 \times\right.$ Green GoTaq ${ }^{\circ}$ Flexi Buffer, pH 8.5), $2 \mathrm{mM} \mathrm{MgCl} 2,400 \mu \mathrm{M}$ dNTPs and $0.3 \mathrm{U}$ of Taq Polymerase. The first round of PCR was performed with 0.48 pmol of primers GOPF and GOPR. Thermocycle was: denaturation at $95^{\circ} \mathrm{C}$ for $5 \mathrm{~min}$, followed by 35 cycles of denaturation at $95^{\circ} \mathrm{C}$ for $1 \mathrm{~min}$, annealing at $58^{\circ} \mathrm{C}$ for $1 \mathrm{~min}$ and extension at $72^{\circ} \mathrm{C}$ for 1 min, with a final extension of at $72^{\circ} \mathrm{C}$ for $15 \mathrm{~min}$.

$1 \mu \mathrm{l}$ of the first-round PCR product along with 0.48 pmol of the primers GIPF and GIPR was used for the second-round PCR. Thermocycle was: denaturation at $95^{\circ} \mathrm{C}$ for $5 \mathrm{~min}$, followed by 35 cycles of denaturation at $95^{\circ} \mathrm{C}$ for $1 \mathrm{~min}$, annealing at $60^{\circ} \mathrm{C}$ for $1 \mathrm{~min}$ and extension at $72^{\circ} \mathrm{C}$ for $1 \mathrm{~min}$, with a final extension of at $72^{\circ} \mathrm{C}$ for $15 \mathrm{~min}$. The amplified products were electrophoresed on $1.2 \%$ agarose gel, stained by ethidium bromide and visualized under ultraviolet light.

\section{Sequencing and Phylogenetic Analysis}

Nested PCR products of gag gene were partially sequenced from Macrogen Inc, Korea, using primer GSP1 (5'-CCATCAATGAGGAAGCTGC-3', nt 14001418, HXB2). The nucleotide sequence spanning the p24 and p7 region of gag gene surrounded by the primers H1Gag1584 (5'-AAAGATGGATAATCCTGGG-3') and g17 (5'-TCCACATTTCCAACAGCCCTTTTT-3') [12], which has been considered for accurate subtyping in previous studies was analyzed. Analysis of the resulting sequences was carried out using Bioinformatic tools described previously [13]. Briefly, the sequences (comprising 460-470 bp) were compared with the sequences from the Los Alamos HIV sequence database. This was accomplished by using the HIV BLAST Search http:// www.hiv.lanl.gov/. The samples were assigned subtypes based on the closest homology found with the subtypes in the Los Alamos database.

Using the same sequence, alignments were obtained by the Clustal $X$ program (1.83) [14]. After alignment, gaps were stripped and minor manual adjustments were made using MacClade [15]. From these alignments, phylogenetic relationships were determined by constructing phylogenetic trees using neighbor-joining method with the help of PAUP* software [16]. Pairwise genetic distances were calculated with Kimura's two parameter method [17].

\section{Results and Discussion}

Sequence alignment and comparison of the partial HIV$1 \mathrm{gag}$ gene from all twenty six IDUs revealed highly congruent topologies. Based on the phylogenetic analysis, the HIV-1 strains from Pakistan clustered closely with HIV-1 subtype A sequences from Senegal and Uganda. The HIV-1 subtype A strains from Pakistan were similar to those circulating in Africa, as opposed to those in neighboring India. Moreover, the HIV-1 strains from Pakistan formed a monophyletic group validating our initial hypothesis of a possible 'founder effect' among the HIV strains from IDU in Karachi.

An identity matrix constructed by BioEdit software revealed more than 98\% similarity among the 26 sequences analyzed, further confirming the 'founder effect' (Additional file 1). In an independent experiment, randomly selected 15 samples were analyzed in a similar way, this time using sequences from HIV nef gene. Once again, a phylogenetic tree was obtained showing high degree of monophylogeny among the studied samples (Additional file 2).

The HIV epidemic is still in its formative stages in Pakistan [18]. The work presented here is the first report that analyses the molecular demographics of HIV spread in this conservative South-East nation. We have demonstrated that the strains circulating amongst this select community of IDUs in Karachi are most likely a consequence of a single-source infection. This finding may well be applicable to other IDU communities in Pakistan that are recording an explosive increase in HIV infection.

In a previous report on the same community of IDUs we indicated to the possible origin of this particular endemic being the overseas commercial workers who had lived in the Middle East over extended period during which they admitted to having had sexual contact with commercial sex workers[10]. We now report deeper analysis of data from the same samples. Close phylogenetic clustering and strong identity among these HIV sequences indicates a "founder effect" of HIV in this 


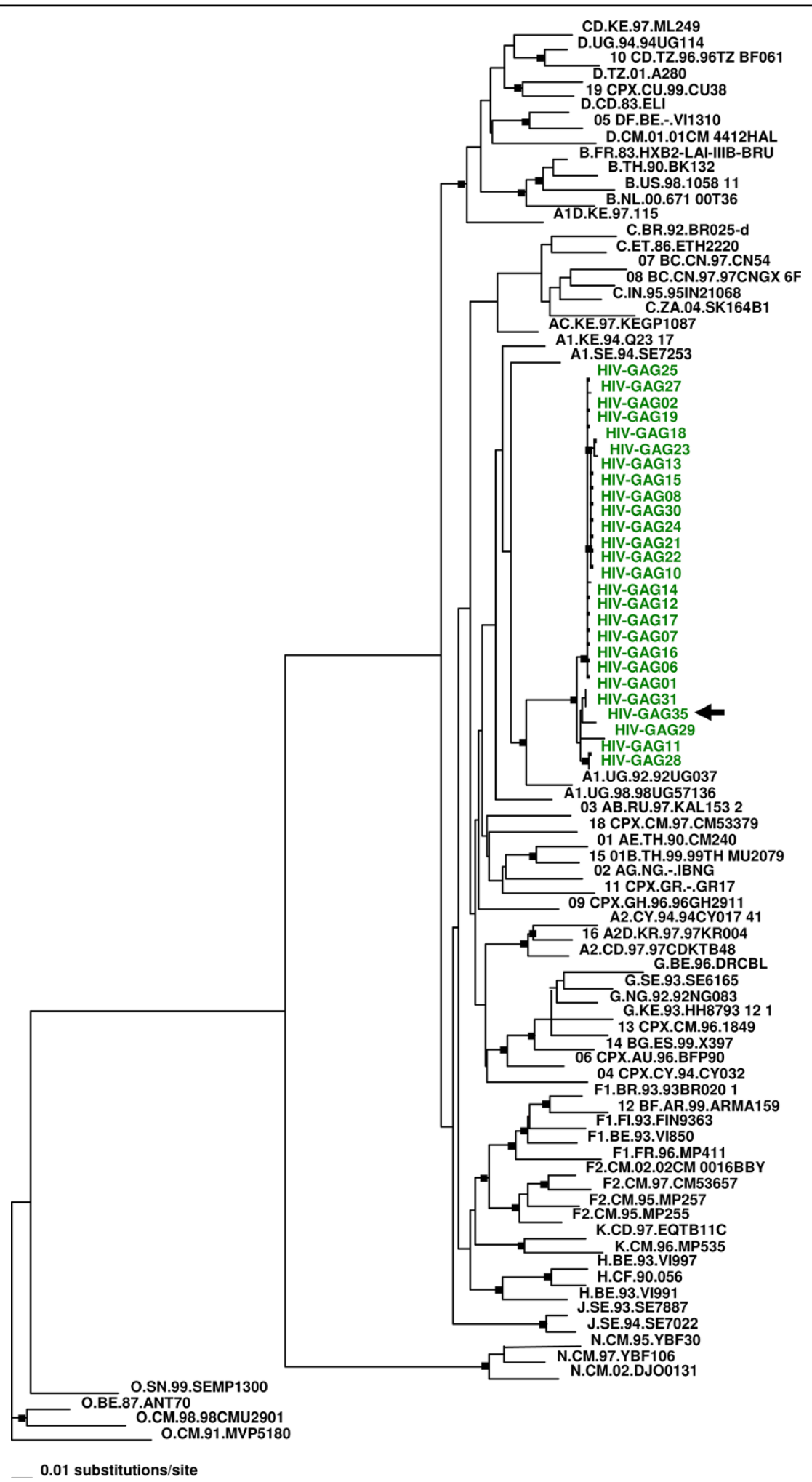

Figure 1 The neighbor-joining (NJ) phylogenetic tree for the 26 sequences (shown in green) of the HIV-gag (p24-p7) region. The tree was constructed by aligning the 26 sequences with HIV reference sequences from Los Alamos database. PAUP* was used to create the tree and distance matrices were generated by using Kimura two-parameter model. The sequence O.CM.91.MVP5180 was used as out group. Closed squares mark the nodes representing bootstrap values $\geq 60$. The arrow on the right points to the study subject (HIV-GAG35) with a history of contact with commercial sex workers during an extended stay abroad. 
community of IDUs, supporting the hypothesis that this entire group of 26 IDUs may have been infected with HIV from a single source. The HIV infection most likely got transmitted to the entire group through exchange of contaminated needles. The study subject HIV-GAG35 has previously reported to having had contact with commercial sex workers during a prolong stay in Sharja, Middle East [10]. During the early nineties, the subject in question was deported, after being tested positive for HIV in Sharja, to Pakistan; thereafter he developed a habit for injecting drugs. The rest of the IDUs were diagnosed positive for HIV in the year 2000 and later. Based on the fact that HIV positive HIV-GAG35 sequence clustered closely with the rest of the IDU samples (Figure 1), we speculate that this patient could be a possible source of infection in this community. That the origin of this particular infection resides in the Middle East is an attractive theory that may be corroborated further through collection and analysis of HIV positive samples from the countries in that region.

During the early nineties, an influx of HIV positive Pakistani deportees from the Middle East constituted a major threat to the transmission of infection in the country [11]. The Pakistani government did respond, albeit inadequately, to this looming disaster. Although commendable efforts were made to devise effective measures to control HIV transmission in the country, a structured program to screen and educate Pakistani migrant workers regarding sexually transmitted infections is still awaited. We have indicated before [18], and emphasize again, that with constant human traffic across borders from Middle East, Afghanistan, and India, and the prevalence of HIV in Pakistan on the rise, clear-cut policies on HIV prevention across borders is urgently warranted.

\section{Conclusions}

The HIV/AIDS epidemic is following along the same atypical lines it has followed in the rest of Asia. Beginning from infection in the high-risk populace, the virus soon traverses the barrier to the general population. Pakistan is already experiencing multiple HIV outbreaks in the IDU community in geographically diverse regions. It would not be long before a steep rise in infection occurs, not unlike its HIV-havocked neighbor, India [19]. HIV-1 is circulating mostly within close-knit communities in Pakistan, such as the IDUs. It is therefore an early opportunity for implementing targeted HIV prevention programs in these vulnerable communities before the infection becomes an issue for the general populace.

Additional file 1: Homology among the IDU sequences. $26 \mathrm{HIV}$ gag sequences from IDUs were aligned using Clustal $X$ and then the idenetity matrix was constructed using the BioEdit software. The matrix shows strong homology ( $98 \%$ or higher identity) among the 26 sequences compared.

Click here for file

[ http://www.biomedcentral.com/content/supplementary/1471-2334-10-7S1.PSD ]

Additional file 2: Clustering of HIV nef IDU sequences. Representative phylogenetic tree, constructed by the CLUSTAL W program, using the neighbor-joining method. The tree is based on the entire nef gene sequence of 15 HIV-1 strains from IDU in Karachi, Pakistan (enclosed in the red box) and $66 \mathrm{HIV}-1$ sequences belonging to various HIV-1 subtypes deposited in the Los Alamos database.

Click here for file

[http://www.biomedcentral.com/content/supplementary/1471-2334-10-7S2.PPT]

\section{Acknowledgements}

This study was partially supported by the Higher Education Commission, Pakistan, grant 20-775, and Pakistan Science Foundation, Pakistan, grant 232, Research Centers in Minority Institutions Program (G12RR003061) and Centers of Biomedical Research Excellence (P20RR018727), National Center for Research Resources, National Institutes of Health. We thank Dr. Shannon Bennett for assistance with sequence analysis.

\section{Author details}

'Department of Biological and Biomedical Sciences, Aga Khan University, Karachi, Pakistan. ${ }^{2}$ Retrovirology Research Laboratory, Department of Tropical Medicine, Medical Microbiology and Pharmacology, Hawaii, USA.

${ }^{3}$ Department of Pediatrics, John A. Burns School of Medicine, University of Hawaii at Manoa, Honolulu, Hawaii 96813, USA. ${ }^{4}$ Department of Microbiology, University of Karachi, Pakistan.

\section{Authors' contributions}

MAR: Performed PCR and sequence analysis and wrote the first draft of the paper. VRN: Developed the study and provided guidance, space and financial support for MAR's work. SKho: Performed PCR and sequence analysis for HIV gag gene. SKha: Helped in collection and extraction of samples. AR: Helped in accessing and surveying the IDU community. RY: carried out part of sequence analysis. SUK: Helped in analysis and interpretation of results. SHA: Supervised the study and arranged for partial funding. All authors have read and approved the submitted manuscript.

\section{Competing interests}

The authors declare that they have no competing interests.

Received: 13 February 2009

Accepted: 12 January 2010 Published: 12 January 2010

\section{References}

1. Khanani RM, Hafeez A, Rab SM, Rasheed S: Human immunodeficiency virus-associated disorders in Pakistan. AIDS Res Hum Retroviruses 1988, 4(2):149-54.

2. Shah SA, Altaf A, Mujeeb SA, Memon A: An outbreak of HIV infection among injection drug users in a small town in Pakistan: potential for national implications. Int J STD AIDS 2004, 15(3):209.

3. Platt L, Vickerman P, Collumbien M, Hasan S, Lalji N, Mayhew S, Muzaffar R, Andreasen A, Hawkes S: Prevalence of HIV, HCV and sexually transmitted infections among injecting drug users in Rawalpindi and Abbottabad, Pakistan: evidence for an emerging injection-related HIV epidemic. Sex Transm Infect 2009, 85(Suppl 2):ii17-22.

4. Agha S: Potential for HIV transmission among truck drivers in Pakistan. Aids 2000, 14(15):2404-6.

5. Baqi S, Kayani N, Khan JA: Epidemiology and clinical profile of HIV/AIDS in Pakistan. Trop Doct 1999, 29(3):144-8.

6. Jamal N, Khushk IA, Naeem Z: Knowledge and attitudes regarding AIDS among female commercial sex workers at hyderabad city pakistan. J Coll Physicians Surg Pak 2006, 16(2):91-3. 
7. Luby SP, Niaz Q, Siddiqui S, Mujeeb SA, Fisher-Hoch S: Patients' perceptions of blood transfusion risks in Karachi, Pakistan. Int I Infect Dis 2001, 5(1):24-6.

8. Bokhari A, Nizamani NM, Jackson DJ, Rehan NE, Rahman M, Muzaffar R, et al: HIV risk in Karachi and Lahore, Pakistan: an emerging epidemic in injecting and commercial sex networks. Int J STD AIDS 2007, 18(7):486-92.

9. Raheel H, White F, Kadir MM, Fatmi Z: Knowledge and beliefs of adolescents regarding sexually transmitted infections and HIV/AIDS in a rural district in Pakistan. J Pak Med Assoc 2007, 57(1):8-11.

10. Khan S, Rai MA, Khanani MR, Khan MN, Ali SH: HIV-1 subtype A infection in a community of intravenous drug users in Pakistan. BMC Infect Dis 2006, 6:164.

11. Shah SA, Khan OA, Kristensen S, Vermund SH: HIV-infected workers deported from the Gulf States: impact on Southern Pakistan. Int I STD AIDS 1999, 10(12):812-4.

12. Heyndrickx L, Janssens W, Zekeng L, Musonda R, Anagonou S, Auwera Van der $G$, et al: Simplified strategy for detection of recombinant human immunodeficiency virus type 1 group $M$ isolates by gag/env heteroduplex mobility assay. Study Group on Heterogeneity of HIV Epidemics in African Cities. J Virol 2000, 74(1):363-70.

13. Khoja S, Ojwang P, Khan S, Okinda N, Harania R, Ali S: Genetic analysis of HIV-1 subtypes in Nairobi, Kenya. PLoS One 2008, 3(9):e3191.

14. Jeanmougin F, Thompson JD, Gouy M, Higgins DG, Gibson TJ: Multiple sequence alignment with Clustal X. Trends Biochem Sci 1998, 23(10):403-5.

15. Maddison DR, Maddison WP: MacClade version 4 Analysis of phylogeny and character evolution Sunderland Massachusetts: Sinauer Associates 2000.

16. Swofford DL: PAUP*: Phylogenetic analysis using parsimony (*and other methods) beta version 4.068 Sunderland, Massachusetts: Sinauer Associates 2001.

17. Kimura M: A simple method for estimating evolutionary rates of base substitutions through comparative studies of nucleotide sequences. $J$ Mol Evol 1980, 16(2):111-20.

18. Rai MA, Warraich HJ, Ali SH, Nerurkar VR: HIV/AIDS in Pakistan: the battle begins. Retrovirology 2007, 4:22.

19. Chandrasekaran P, Dallabetta G, Loo V, Rao S, Gayle H, Alexander A: Containing HIV/AIDS in India: the unfinished agenda. Lancet Infect Dis 2006, 6(8):508-21.

\section{Pre-publication history}

The pre-publication history for this paper can be accessed here:http://www. biomedcentral.com/1471-2334/10/7/prepub

doi:10.1186/1471-2334-10-7

Cite this article as: Rai et al.: Evidence for a "Founder Effect" among HIV-infected injection drug users (IDUs) in Pakistan. BMC Infectious Diseases 2010 10:7.

\section{Publish with Biomed Central and every scientist can read your work free of charge}

"BioMed Central will be the most significant development for disseminating the results of biomedical research in our lifetime. "

Sir Paul Nurse, Cancer Research UK

Your research papers will be:

- available free of charge to the entire biomedical community

- peer reviewed and published immediately upon acceptance

- cited in PubMed and archived on PubMed Central

- yours - you keep the copyright 